\title{
In reply: Optimal propofol induction dose in morbidly obese patients: bispectral index guidance is not the answer
}

\author{
Yamini Subramani, MD • Waleed Riad, MD, AB, SB, KSUF • \\ Frances Chung, MBBS, FRCPC $\cdot$ Jean Wong, MD, FRCPC
}

Received: 9 April 2018/Accepted: 9 April 2018/Published online: 24 April 2018

(C) Canadian Anesthesiologists' Society 2018

\section{To the Editor,}

We thank Dr. Chiravuri and colleagues for their valuable comments ${ }^{1}$ on our randomized controlled trial. ${ }^{2}$ Dr. Chiravuri indicated that the bispectral index (BIS) is a brain-state monitor and was not designed to guide anesthetic induction. However, there is precedent in the literature that a BIS target of 50 may be used as an end point of induction. ${ }^{3,4}$ Because of the lack of data in the literature, our objective was to determine if the BIS monitor is an appropriate approach to guiding induction of anesthesia in morbidly obese (MO) patients.

In their letter, Chiravuri et al. stated that the two groups were randomized as follows: "Propofol dosing based on: 1) the calculated lean body weight (LBW group), or 2) propofol infusion $100 \mathrm{mg} \cdot \mathrm{kg}^{-1} \cdot \mathrm{hr}^{-1}$ to an initial targeted BIS of 50 (BIS group)." We want to clarify that both the LBW and the BIS groups received the same propofol infusion of $100 \mathrm{mg} \cdot \mathrm{kg}^{-1} \cdot \mathrm{hr}^{-1}$ based on the LBW. The LBW was calculated based on the Janmahasatian equation. ${ }^{5}$ The LBW group received this infusion until a

Y. Subramani, MD · W. Riad, MD, AB, SB, KSUF .

F. Chung, MBBS, FRCPC · J. Wong, MD, FRCPC $(\square)$

Department of Anesthesia, Toronto Western Hospital, University

Health Network, Toronto, ON, Canada

e-mail: jean.wong@uhn.ca

W. Riad, MD, AB, SB, KSUF

Department of Anesthesia, Corniche Hospital, Abu Dhabi, United Arab Emirates predetermined dose of $2.6 \mathrm{mg} \cdot \mathrm{kg}^{-1} \mathrm{LBW}$ was reached, whereas the BIS group received the infusion until a BIS target of 50 was reached. As explained in our article, the BIS target of 50 is based on studies by Gürses et al. ${ }^{4}$ and Arya et al., ${ }^{3}$ which compared the clinical end point of the loss of verbal response with BIS for induction with propofol, using a mean (standard deviation) BIS of 48 (2) as an end point for induction. The $2.6 \mathrm{mg} \cdot \mathrm{kg}^{-1} \mathrm{LBW}$ dose of propofol was based on the results obtained in the study conducted by Ingrande et al., which showed that the LBW scalar is appropriate for inducing MO patients with propofol. ${ }^{6}$ This initial dosing was defined as a target point. However, the infusion was continued until the Observer's Assessment of Alertness/Sedation Scale ${ }^{7}$ was 0, which was taken as an end point for induction. The doses at the target points and infusion end points are reported based on both total body weight and LBW for both groups in Table 3 of our article. ${ }^{2}$ We emphasize that both groups received the infusion in the same manner, but the targets were different - i.e., LBW-based dosing vs BIS-based dosing.

We agree that MO patients should be included during the drug-development stage because there is currently no consensus on dosing of anesthetic agents in MO patients due to the paucity of data. This is particularly important given the obesity epidemic. Our study - one of the very few studies examining the application of BIS for anesthetic induction in MO patients - provides promise that BIS may be useful in this regard.

Conflicts of interest None declared.

Editorial responsibility This submission was handled by Dr. Hilary P. Grocott, Editor-in-Chief, Canadian Journal of Anesthesia. 


\section{References}

1. Chiravuri D, Owusu-Bediako K, Nafiu OO. Optimal propofol induction dose in morbidly obese patients: bispectral index guidance is not the answer. Can J Anesth 2018; 65: DOI: https:// doi.org/10.1007/s12630-018-1134-y.

2. Subramani Y, Riad W, Chung F, Wong J. Optimal propofol induction dose in morbidly obese patients: a randomized controlled trial comparing the bispectral index and lean body weight scalar. Can J Anesth 2017; 64: 471-9.

3. Arya S, Asthana V, Sharma JP. Clinical vs. bispectral index-guided propofol induction of anesthesia: a comparative study. Saudi J Anaesth 2013; 7: 75-9.
4. Gürses E, Sungurtekin H, Tomatir E, Dogan H. Assessing propofol induction of anesthesia dose using bispectral index analysis. Anesth Analg 2004; 98: 128-31.

5. Janmahasatian S, Duffull SB, Ash S, Ward LC, Byrne NM, Green $B$. Quantification of lean bodyweight. Clin Pharmacokinet 2005; 44: 1051-65.

6. Ingrande J, Brodsky JB, Lemmens HJ. Lean body weight scalar for the anesthetic induction dose of propofol in morbidly obese subjects. Anesth Analg 2011; 113: 57-62.

7. Chernik DA, Gillings D, Laine $H$, et al. Validity and reliability of the Observer's Assessment of Alertness/Sedation Scale: study with intravenous midazolam. J Clin Psychopharmacol 1990; 10: 24451. 